\title{
COVID-19 and the City: A Healthy City Strategy for Pandemic Challenges, from Planning to Action
}

\author{
Hamzah Hasyim ${ }^{*}$, Patricia Dale ${ }^{2}$
}

\begin{abstract}
${ }^{1}$ Department of Environmental Health, Faculty of Public Health, Sriwijaya University, South Sumatra Province, Indonesia
${ }^{2}$ Centre for Planetary Health and Food Security (CPHFS) School of Environment and Science, Griffith University, Queensland, Australia
\end{abstract}

\begin{abstract}
COVID-19 is a respiratory disease caused by SARS-CoV-2, a new coronavirus discovered in 2019. WHO declared COVID-19 is a respiratory disease caused by SARS-CoV-2 as a pandemic that the detection level of cases changed daily, and it can track almost in real-time. This paper used a narrative literature review to address issues of urban quality and lack of exercise. The specific aim was to discuss the concept of a healthy city, indicate a new urban model, and advocate for the increased use of bicycles, outdoor gym/outdoor exercise, walking to reducing pollution, and improving physical, psychological, and social fitness. A healthy city can improve residents' health by improving conditions of life to face COVID-19 pandemics. It needs the local capacity to prevent the spread of the diseases and design public health concepts concerning the built environment and contemporary towns in a new urban model. Dialogue opportunities in public health can provide essential guidance for designers (architects and town planners), decision-makers, public health experts, and health agencies locally, promoting the actions and policies to transform the city into a healthier neighborhood and salutogenesis.
\end{abstract}

Keywords: city by bike, COVID-19, healthy city, new urban model

\section{Introduction}

COVID-19 is a respiratory disease caused by SARSCoV-2 (coronavirus 2019; previous 2019 - nCoV), a new coronavirus discovered in 2019. The virus is transmitted from person to person through respiratory secretions and contact, mainly through sneezing and coughing. ${ }^{1}$ The novel coronavirus outbreak has spread to many other countries. On January 30, 2020, the Committee of Emergency World Health Organization (WHO) announced a global health emergency based on notifications of cases that continued to increase in China and other international locations. It was declared a pandemic by the WHO. ${ }^{2}$ The detection level of issues changes every day and can be tracked almost in real-time on the website provided by Johns Hopkins University and others forums. WHO has recorded more than 96 million cases of pandemic COVID-19 occurring globally, with the possibility of doubling and more than two million deaths confirmed. ${ }^{3}$ Globally, as of 4:52 p.m. CEST, June 9, 2021, there have been $173,674,509$ confirmed cases of COVID-19, including $3,744,408$ deaths, reported to WHO. As of June 7, 2021, a total of 2,092,863,229 vaccine doses have been administered. ${ }^{4}$

Correspondence*: Hamzah Hasyim, Department of Environmental Health, Faculty of Public Health, Sriwijaya University, South Sumatra Province, Indonesia, E-mail: hamzah@fkm.unsri.ac.id, Phone +62 (711) 580068; Fax +62 (711) 580089
Pandemics in the 20th and 21 st century are primarily transmitted through direct contact with body fluids (AIDS, Ebola) or breathing (pandemic influenza, SARS$\mathrm{CoV}-2$ Mers), in contrast to the past, when the oral-fecal (Cholera) or vectorial (Malaria, Plague) routes predominated and could be controlled by public health sanitation. It has led to dramatic action in many countries, e.g., China, Singapore, Japan, Italy, Spain, and many other countries. In those areas, lockdown, social distancing, hand sanitizing, and wearing masks have been and, in some, still are mandatory. ${ }^{5}$

On the other hand, urban density, population, and housing favor the spread of COVID-19 in living quarters and at meetings, and on public transport. One of the studies aimed to understand the urban-centric nature of the infection found that transit mediums, especially rail and aviation, were positively associated. 6 The risk of transmission COVID-19 is enhanced by the proximity of people, inequality of economic and social conditions, which in turn, are associated with housing the poor and uncertain conditions of life. ${ }^{7,8}$ Currently, according to the United Nations, $55 \%$ of the world's population live in cities, and this is expected to rise to $68 \%$ by $2050 .{ }^{9}$ To

Received : June 7, 2021

Accepted : July 15, 2021

Published: July 31, 2021 
take effective measures in addressing urban health, the various sectors need to be integrated (i.e., a holistic intersectoral approach). Stakeholders include the health and other government departments, non-government organizations, the private sector, and the public. A Healthy City project aims to bring together public, private, and voluntary partnerships to focus on urban health problems in a participatory manner broadly and improve residents' health by improving conditions of life. Thus, developing a cross-sectoral approach integrated with community participation is an essential feature of healthy cities.

In addition, environmental planning and design for public health are essential. Data from several sources have identified that airborne viruses are carried on fine particles spreading into the environment. Deforestation, global warming, and atmospheric pollution can accelerate the spread of viruses such as SARS-CoV-2.10 Another study investigated the relationship between air pollutants and COVID-19 spread in Jakarta, Indonesia, during the impact of large-scale social restriction (LSSR). During the LSSR period, the air pollution index (API) of $\mathrm{PM}_{2.5}$, $\mathrm{PM}_{10}, \mathrm{CO}, \mathrm{SO}_{2}$, and $\mathrm{NO}_{2}$ decreased by $9.48 \%, 15.74 \%$, $29.17 \%, 6.26 \%$, and $18.34 \%$, respectively. In contrast, $\mathrm{O}_{3}$ increased by $4.06 \%$. Another study discovered significant positive correlations between $\mathrm{SO}_{2}, \mathrm{CO}$, and $\mathrm{PM}_{2.5}$ and COVID-19 cases. The area has become vulnerable to COVID-19 infection due to $\mathrm{SO}_{2}, \mathrm{CO}$, and $\mathrm{PM}_{2.5}$ exposure. ${ }^{11}$

The health of city populations depends on the condition of life and style of living. Factors in the day-to-day life, which significantly affect health status, are referred to as "determinants of health." These include the availability of water, sanitation, nutrition, food safety, health care, housing and working conditions, education, lifestyle, demography, and changes in income. In addition, environmental, physical, social, and economic factors are included. Improving the determinants of health is not easy in many situations. Encouraging increased use of bicycles, outdoor gym/outdoor exercise, walking to reducing pollution, and improving physical, psychological, and social fitness is a continuing concern within a healthy city's concept.

For this reason, it needs comprehensive action to deal with the COVID-19 pandemic, not only in implementing the health protocol of COVID-19 but also applying the concept of a healthy city, which reduces environmental pollution and also provides health benefits to people. For example, outdoor gym/outdoor exercise, walking, and cycling contribute to reducing air pollution and improving the community's physical, psychological, and social fitness. Therefore, this article aimed to discuss the concept of a healthy city, suggest a new urban model, and advocate for increased outdoor exercise, including bicycle use and walking, and providing activity that reduces air pollution. This study also offered a strategic direction with some focus on Indonesia.

\section{Method}

This article conducted a narrative literature review using ScienceDirect search engine. The inclusion criteria were literature searched from 2020 to 2021 (the last two years) based on keywords relevant to the topics of interest. The searches included the terms of: "healthy city strategy," "new urban model," and "city by bike" in connection with COVID-19. The kind of article was recorded, for example, if it was a review or a research article and if available with Open Access. Articles that were not available in Open Access were excluded. The articles selected were analyzed qualitatively based on the information about healthy city strategy, new urban model, and city by bike and in the context of COVID- 19 .

\section{Results}

The recent paper using a narrative literature review by ScienceDirect engine, found 61 articles, 51 in 2021 and 10 in 2020, with seven review articles and 54 research articles. There were 22 kinds of Open Access articles, 19 in 2021 and 3 in 2020 selected based on exclusion and inclusion criteria. These included one review article and 21 research articles in a range of areas

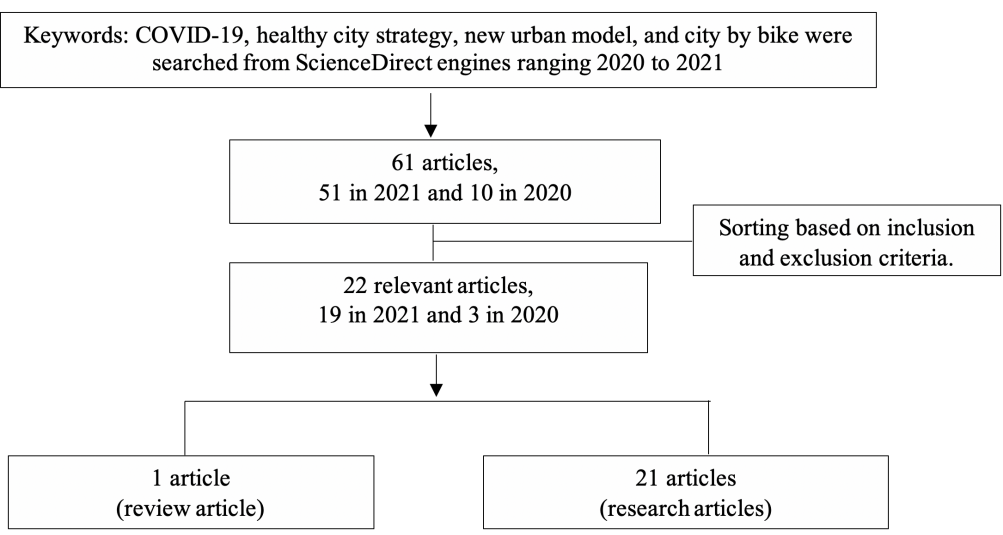

Figure 1. A Literature Search from ScienceDirect Engines 
including Social Sciences, Engineering, Environmental Science, Decision Sciences, Medicine and Dentistry, Economics, Econometrics and Finance, and Energy.

Finally, the articles were reviewed and discussed using a comprehensive, critical, and objective analysis of the current knowledge to lead to a healthy city strategy to minimize COVID-19 and improve the community's general health. The literature search strategy from ScienceDirect engines is shown in Figure 1.

Critical articles reported in the scoping review helped identify lessons learned for cities from the COVID-19 pandemic in the post-pandemic era. Moglia et al. outlined three urban missions to guide a green urban recovery. These are to speed up the changes to urban mobility, achieve sustainable urban development, and build resilient urban infrastructure. They defined six transition pathways for urban mobility, energy, food, housing, health, and nature. These pathways can provide a roadmap for green recovery in cities while also increasing resilience. ${ }^{12}$ Given that recent evidence predicts that urban cycling will continue to grow in Latin American cities, it is critical to implement policies and educational/training improvements to improve cyclist safety and health in the cities. ${ }^{13}$ To become sustainable, cities are experiencing transformative changes. Identifying and describing the increasing adoption of big data technologies can assist policymakers and planners in assessing the benefits and costs when implementing sustainable urban transformations. ${ }^{14}$

\section{Discussion}

Exploring a Healthy City strategy to deal with a pandemic is a challenge from planning to action. This section discusses the following areas: a healthy city, a new urban model, and a city by bike (increased exercise and pollution reduction).

\section{Healthy City}

World Health Organization (WHO) published a manifesto for healthy and green recovery from COVID-19, including building healthy and decent habitation. Creating a healthy city is important during Pandemic COVID-19, which requires support and investment. Healthy cities are defined as cities that constantly develop and improve the physical and social environment and expand the power base of communities that enable people to support each other to carry out all life functions mutually. Healthy Cities is a global attempt to prioritize the agenda for a social, economic, and political government town. For the past 30 years, the WHO European Healthy Cities Network has included approximately 100 major cities and about 30 national networks.

Population growth in urban areas is a global phenomenon, and countries in the Pacific West area are no exception. It is great to make cities carbon neutral, more habitable, and healthier by transport and city planning. Recently, the WHO for the Region Pacific West has been working together with its members, developing several Healthy City initiatives to improve the health of urban areas. However, it is not easy to measure the results: an index is required, standards set, and the impact of each component of health needs to be determined. It further supports the idea that rating the effect of fitness is required to develop public policy.

Furthermore, the main features of the Healthy City project include a political commitment with high levels of collaboration amongst the cross-sectoral community; community participation; integration of activities; development of urban health profiles and local action plans; monitoring and evaluation periodically. In addition, there needs to be participatory research and analysis, sharing information, media engagement, the incorporation of views from all groups in the community, sustainability mechanisms, connection with society and the development of human beings, and national and international networks. The measurement involves ten metrics of healthy lifestyles, including the rate of obesity and pollution levels. Each metric is assigned a score, which is then added to yield a score out of 100. The Spotahome Healthiest Cities Index showed that Amsterdam was number one in 2018. ${ }^{15}$

Information about public health can provide valuable rules and guidance for designers (architects and town planners), decision-makers, expert public health, and health agencies locally, promoting holistic policies and actions to transform the city into more healthy neighborhoods. ${ }^{16}$ These factors may explain the relatively good correlation between a multidisciplinary approach to develop systemic operational skills capable of dealing with complexity and a paradigm for assessing the effects of the current pandemic. The contemporary challenge is how to re-design public health concepts concerning the built environment and new cities? The following section considers this question, with examples from cities that have implemented a healthy city approach and standards of human behavior to minimize COVID-19 transmission.

\section{New Urban Model}

Urbanization can reduce human hardship and suffering, so urban health development must create sustainable urban communities, promoting healthy living, cross-sectoral approaches and political will, and comprehensive urban renewal programs. ${ }^{17}$ Previous studies have demon-strated that urbanization has taken place rapidly in the past two decades. ${ }^{18}$ Urbanization is expected to continue in the years to come, particularly in developing countries. While urbanization provides opportunities for employ-ment, education, and socioeconomic development, it also raises several issues of health detriment related to determinants of health (intro- 
duced above). Health is related to the adequacy of medical health services. However, it is also associated with the urban physical, social, and economic environment, and society's lifestyle and behavior. Planning can remediate some of the health problems caused by poor quality in the determinants. Therefore, the solution to the problem of urban health areas requires the effective involvement of the nonhealth sector (e.g., industry, transport, energy work, education, commerce, utilities, and services the City, planning the City, and other similar items). Besides, it included the organization of nongovernmental, private sector, and community.

In some cities, a new planning concept has been introduced to overcome planning problems, and it includes the condensed City, large blocks, 15-Minute City away, car-free, or a combination of them. Condensed (or 'solid') cities are characterized by a high density of settlements and shorter travel distances. They have lower emissions of $\mathrm{CO}_{2}$ than extensive cities and are healthier because of the diverse land use, briefer travel trips, and the opportunity for healthier mobility options. For example, Barcelona (Spain) plans to make more than 500 superblocks to reduce vehicle motor traffic and provide more space for people, traveling is active, and green space. ${ }^{19}$ This superblock will reduce air pollution, noise levels, and heat islands effects while increasing green space and physical activity. It is estimated that they can prevent nearly 700 premature deaths in the city each year.

Similar principles were applied in other countries. France introduced a model of the 15-Minute City so that places of work, school, entertainment, and activities of others can be reached within 15 minutes walking. The 15-Minute City concept is a quite radical approach and will require monitoring. ${ }^{20}$ It also provides the possibility of reducing inequality as it is a model that involves the mixing of groups of the population that differs from a model zoning settlement related to the status of the social economy. It also will reduce travel distance and thus reduce both $\mathrm{CO}_{2}$, air pollution, and noise level. Hamburg (Germany) plans to be free from cars by 2034 to over-

come the climate crisis. ${ }^{21,22}$ A car-free city reduces personal motor vehicle use and can provide easy access to public transport and increase physical activity. Another successful example is Vauban in Freiburg, Germany, with a neighborhood without cars and sustainable housing. To conclude this section, the healthy city strategy reduces air pollution and noise levels, increases physical activity, and creates space for green areas - the new urban models of urban reverse the planning pyramid for transport.

As well as planning, other measures are needed to minimize disease transmission in particular circumstances. For COVID-19, most countries imposed national lockdowns and social distancing policies to control its rapid dispersion. Several studies investigating the lock- down effectively managed and prevented the spread of the pandemic. Nevertheless, the study's findings were reminders to continue addressing air pollution issues to protect human health. ${ }^{23}$ As a result, the critical regions with widespread confirmed cases of COVID-19 should be urged to maintain lockdown. It is encouraging to compare pre COVID-19 air pollution with that found during the lockdown period. Industrial and mobility activities were reduced, and selected pollutants: $\mathrm{NO}_{2}$, $\mathrm{PM}_{2.5}$, and $\mathrm{PM}_{10}$ emissions were reduced by approximately $20-40 \%$ in 2020.24 It is essential to measure atmospheric chemistry, emission trends, and meteorology lockdown effects on pollutant concentrations. ${ }^{25}$ In addition, Hypoxia is observed in COVID-19 patients; however, patients exhibit a distinct phenotype. Intracellular nitric oxide (NO) levels are essential in the vasodilation of small vessels. 26

From the previous discussion, it is recommended that planners generally prioritize public transportation, walking on foot, and cycling instead of prioritizing the car. Expanding bicycle use and increasing the cycling speed is one way to reduce the cross-vehicle motor and emissions of $\mathrm{CO}_{2}$ and increase people's activity. Increased physical activity also improves public health. Mobility actively gives people the opportunity to physically build a movement in everyday life during daily trips because they often do not have enough time to go to the gym. Progress has been achieved in creating and expanding bike tracks, but this will only succeed if the tracks are well marked, secure, and part of the network. Besides, in the concept New Urban Model, physical activity (PA) and the use of digital facilities by citizens increased during the COVID-19 pandemic; the first increased fitness and reduced close personal contacts. 27,28 The next section focuses on alternative transportation, especially the use of bikes.

\section{City by Bike}

It has been demonstrated that implementing the health protocol of COVID-19 and applying the concept of healthy city results in preventing or reducing COVID-19. Here the focus is on bicycles (bikes). Cycling, in general, can help usher in a postcoronavirus society. ${ }^{29}$ The Netherlands is known as a cyclist-friendly city. Citizens more often choose to travel by bicycle, the foot or using public transport. Cycling is a cost-effective solution. These results were consistent with those of other studies and suggest that bike-sharing advantages help respond to the COVID-19 pandemic and reduce air pollution. ${ }^{16,30}$

The effects of COVID-19 on the transportation sector are being studied extensively. Transport policies (e.g., for the use of bikes) can lead to reducing social contact to limit infection rates by using online platforms to deliver materials and food). ${ }^{31,32}$ The COVID-19 pandemic has resulted in a dramatic shift in the demand for safe and physically segregated outdoor walking, cycling and com- 
merce spaces. Cities worldwide have responded by enacting various policies and programs aimed at addressing these changes. ${ }^{33}$ In Switzerland, cycling is increasing, especially if there is an increase in traffic congestion, and is becoming a habit. ${ }^{34}$ Bike-sharing can help respond to the COVID19 pandemic. ${ }^{30}$ It has been found that the possibility of infection occurs in public transportation, so that, in a COVID-19 situation, bikes are a recommended alternative, if possible. ${ }^{30,35}$ There is a significant potential for e-bikes as a substitute for public transportation in post-pandemic cases. These findings can develop appropriate first policy interventions in future urban transport strategies to promote and strengthen bicycle sharing. 36,37 The COVID-19 pandemic is revealed from the pattern of urban mobility. Green Europe offers a 'road map' of a comprehensive strategy that aims to create a more frugal European Union with power and sustainability and a great opportunity to make cities carbon neutral. 38 As well, cities can be more habitable and healthier through better urban and transport planning.

More details about bikeways are provided in the following, with examples of implementation. One of the ways that can be taken is properly assigning tracks (bike lanes). The width of the bike track in Bangkok, Thailand, is about 1.4 meters. Hiking is given the color green with a picture of people riding bicycles on it. Bike tracks are explicitly made in between asphalt and pavement. The dividing lines for bikes use a separator colored yellow as high as $30 \mathrm{~cm}$. In Singapore, through the Land and Transport Authority (LTA) body and several bodies, the Ministry of Transport organizes the City. It equipped it with bike tracks targeting the $700 \mathrm{~km}$ track bike that covers the entire country. Bicycle lanes in Singapore were made by reducing and managing the pedestrian footpath. In the settlement area, particular pathways come with signs mainly for cyclists. Some lines mark the park connector network $(\mathrm{PCN})$ or network that can move from park to park and other city gardens. Each lane is equipped with manual directions to facilitate cyclists getting to the desired location. Singapore is widely equipped with areas for parking bicycles. The Netherlands is referred to as one of the cities most friendly to cyclists. Amsterdam was called a paradise for cyclists in the world. The development of bicycles took some time. Previously, after the second world war, the existence of bikes was eroded by cars. The Netherlands has started to implement the Woonerf system or share the joint road for a variety of users. 39

The Woonerf system is designed to slow the driver as cars, bicycles, and pedestrians share the same space. There is no special separator that limits bicycle lanes to motorized vehicles, only a white line, both of which are confined. Göttingen, Germany, is considered cyclistfriendly. Some regulations prohibit the honking (harassing) of cyclists by cars and motorcycles. The bike path in the city is only about three meters wide. Typically, bike tracks were given a different color from the pedestrian lanes. In Germany, bike trails are not restricted to the City but may have intercity links. Bikes are safe and comfortable, and cyclists' facilities, including places to park bikes, are also reasonably plentiful.

Bike paths in Moscow, Russia, are similar to those in Singapore. The bicycle paths in Moscow, nicknamed a thousand parks, almost connect the entire City. One of them is in Gorky Park, in which the bike path can be connected to the metro or stations. Locating bike tracks on the pavement beside roadways eliminates the possibility of collision with vehicles such as cars or motorcycles. For additional safety, closed-circuit television (CCTV) constantly monitors every street corner in case there is a violation. There are many bicycle rental locations in Denmark. In the town, bike tracks are located on the right of the asphalt road. There is a bit of pavement between bike lanes and the road - highway. During busy times in Copenhagen, $62 \%$ of the population travels by bicycle to work or study. At each intersection, the bike path is colored blue. There are also traffic and other lights that are specifically for the bike. Electric bicycles are also allowed to use the bike tracks. Every building must have a bicycle park. The number of parked bicycles is not small as in Indonesia. There are dozens of bikes parked in buildings. Motor vehicle riders prioritize pedestrians, so this should minimize harm to walkers. Many bridges are reserved for the bike rider.

\section{Strategyc Direction (Indonesia)}

All the concepts discussed above emphasize access to green space, which is essential for various reasons, including mental health, cognitive function, and hope for the future. Strategies are needed to create green spaces such as gardens and to introduce more vegetation in the streets. Where feasible, it needs to dig up the asphalt and plant many trees, which will reduce the urban heat effect, contribute to the absorption of $\mathrm{CO}_{2}$, and is a health benefit. The Jakarta Provincial Government is stepping up bike lanes to reduce traffic congestion and air pollution. A 200-kilometer build bicycle lane with a pattern of "35," i.e., every 5 meters of white-lined bicycle lanes, there will be a 3-meter-long green marking block. The comprehensive proposal of around sixty-two billion (IDR) is to construct an advanced bicycle path. Previously, Jakarta was also awarded the Sustainability Transportation Awards (STA). Jakarta was the first City in Southeast Asia to get the award in the area of transportation. ${ }^{40}$

\section{Conclusion and Recommendation}

A healthy city strategy to manage the COVID-19 pandemic is a challenge and must cover planning and action. Healthy city concepts provide a multidisciplinary approach for involving people such as architects and city 
designers, decision-makers, public health experts, and local health authorities, promoting measures and procedures to transform the city into a healthier place, with more amenable neighborhoods during the COVID-19 pandemic. Some cities have introduced a New Urban Model that includes managing population density, green space, and transport. Planning for a car-free city that reduces air pollution will create a healthier environment. Promoting walking and outdoor exercise outdoor gym/outdoor exercise encourages safe physical activity and increases existing green space. Cycling is an inexpensive form of exercise and contributes to reducing pollution and improving physical, psychological, and social fitness/health to increase endurance necessary for the COVID-19 pandemic.

\begin{abstract}
Abbreviations
COVID-19: coronavirus disease 2019 caused by SARS-CoV-2; SARSCoV-2: Severe Acute Respiratory Syndrome Coronavirus-2 previously provisionally named 2019 novel coronavirus or 2019-nCoV (Lai, Shih 2020); CCTV: closed-circuit television; EU: European Union countries; IDR: Indonesian Rupiah; LTA: Land and Transport Authority; Mer's: Middle East Respiratory Syndrome; PA: the physical activity; PM10: Particulate Matter of 10 Microns in diameter or smaller People-inMonitoring; WHO: World Health Organization.
\end{abstract}

\section{Ethics Approval and Consent to Participate}

Not applicable.

\section{Competing Interest}

The authors declare no competing interests.

\section{Availability of Data and Materials}

The authors have full access to all the data in the study and take responsibility for the data integrity.

\section{Authors' Contribution}

$\mathrm{HH}$ conceived the study. HH and PD wrote the main manuscript text, and all authors contributed to interpreting the results. All authors read and approved the final manuscript.

\section{Acknowledgment}

Not applicable.

\section{References}

1. Russell CD, Millar JE, Baillie JKJTL. Clinical evidence does not support corticosteroid treatment for 2019-nCoV lung injury. 2020;395(10223):473-5.

2. Motlagh A, Yamrali M, Azghandi S, Azadeh P, Vaezi M, Ashrafi F, et al. COVID19 prevention \& care; a cancer specific guideline. 2020;23(4):255-64.

3. Meters W. COVID-19 Coronavirus Pandemic 2021; 2021.
4. World Health Organization. WHO Coronavirus (COVID-19) Dashboard 2021; 2021.

5. Ferguson NM, Laydon D, Nedjati-Gilani G, Imai N, Ainslie K, Baguelin $\mathrm{M}$, et al. Impact of non-pharmaceutical interventions (NPIs) to reduce COVID-19 mortality and healthcare demand. Imperial College COVID-19 Response Team. 2020:20.

6. Gupta D, Biswas D, Kabiraj PJG. COVID-19 outbreak and Urban dynamics: regional variations in India. 2021:1-19.

7. Allaria $\mathrm{C}$, Loubière $\mathrm{S}$, Mosnier $\mathrm{E}$, Monfardini $\mathrm{E}$, Auquier $\mathrm{P}$, Tinland $\mathrm{A}$. "Locked down outside": perception of hazard and health resources in COVID-19 epidemic context among homeless people. SSM -Population Health. 2021;15:100829.

8. Galanis $\mathrm{G}$, Hanieh A. Incorporating social determinants of health into modelling of COVID-19 and other infectious diseases: a baseline socio-economic compartmental model. Social Science \& Medicine. 2021;274:113794.

9. United Nations. $68 \%$ of the world population projected to live in urban areas by 2050, says UN 2018; 2018.

10. Wu X, Nethery RC, Sabath BM, Braun D, Dominici F. Exposure to air pollution and COVID-19 mortality in the United States. J MedRxiv; 2020.

11. Rendana M, Komariah LN. The relationship between air pollutants and COVID-19 cases and its implications for air quality in Jakarta, Indonesia. Jurnal Pengelolaan Sumber Daya Alam dan Lingkungan. 2021;11(1):93-100.

12. Moglia M, Frantzeskaki N, Newton P, Pineda-Pinto M, Witheridge J, Cook S, et al. Accelerating a green recovery of cities: lessons from a scoping review and a proposal for mission-oriented recovery towards post-pandemic urban resilience. Developments in the Built Environment. 2021;7:100052.

13. Useche SA, Esteban C, Alonso F, Montoro L. Are Latin American cycling commuters "at risk"? A comparative study on cycling patterns, behaviors, and crashes with non-commuter cyclists. Accident Analysis \& Prevention. 2021;150:105915.

14. Bibri SE. Data-driven smart sustainable cities of the future: an evidence synthesis approach to a comprehensive state-of-the-art literature review. Sustainable Futures. 2021;3:100047.

15. Anonymous. The world's healthiest cities: Spotahome Cities Barcelona Berlin Brussels Dublin London Madrid Milan Rome Valencia; 2021.

16. Capolongo S, Rebecchi A, Buffoli M, Appolloni L, Signorelli C, Fara GM, et al. COVID-19 and Cities: from Urban Health strategies to the pandemic challenge. A Decalogue of Public Health Opportunities. Acta bio-medica : Atenei Parmensis. 2020;91(2):13-22.

17. Aliyu AA, Amadu L. Urbanization, cities, and health: the challenges to Nigeria - A review. Ann Afr Med. 2017;16(4):149-58.

18. Tonne C, Adair L, Adlakha D, Anguelovski I, Belesova K, Berger M, et al. Defining pathways to healthy sustainable urban development. Environment international. 2021;146:106236.

19. Roberts D. Barcelona wants to build 500 superblocks. Here's what it learned from the first ones. Vox Media, LLC.; 2019.

20. Pozoukidou G, Chatziyiannaki Z. 15-Minute City: decomposing the New Urban planning Eutopia. Sustainability. 2021;13(2):928.

21. Nuwer R. Hamburg Plans to Become Car-Free By 2034 But should there really be zero cars? Smithsonian Magazine; 2014. 
22. Urry J, Leach J, Dunn N, Coulton C. The little book of car free cities. Lancaster University; 2017.

23. Pei L, Wang X, Guo B, Guo H, Yu Y. Do air pollutants as well as meteorological factors impact Corona Virus Disease 2019 (COVID-19)? Evidence from China based on the geographical perspective. Environmental Science and Pollution Research; 2021.

24. Skirienè AF, Stasiškienè Ž. COVID-19 and air pollution: measuring pandemic impact to air quality in five European countries. Atmosphere. 2021;12(3):290.

25. Gkatzelis GI, Gilman JB, Brown SS, Eskes H, Gomes AR, Lange AC, et al. The global impacts of COVID-19 lockdowns on urban air pollution : a critical review and recommendations. Elementa: Science of the Anthropocene 2021;9(1).

26. Mortaz E, Malkmohammad M, Jamaati H, Naghan PA, Hashemian SM, Tabarsi P, et al. Silent hypoxia: higher NO in red blood cells of COVID-19 patients. BMC Pulmonary Medicine. 2020;20(1):269.

27. Palacin V, Ferrario MA, Hsieh G, Knutas A, Wolff A, Porras J. Human values and digital citizen science interactions. International Journal of Human-Computer Studies. 2021;149:102605.

28. Katewongsa P, Widyastari DA, Saonuam P, Haemathulin N, Wongsingha N. The effects of the COVID-19 pandemic on the physical activity of the Thai population: evidence from Thailand's surveillance on physical activity 2020. Journal of sport and health science. 2021;10(3):341-8.

29. Teixeira JF, Lopes M. The link between bike sharing and subway use during the COVID-19 pandemic: the case-study of New York's citi bike. Transportation Research Interdisciplinary Perspectives. 2020;6:100166.

30. Jobe J, Griffin GP. Bike share responses to COVID-19. Transportation Research Interdisciplinary Perspectives. 2021;10:100353.

31. Zhang J, Hayashi Y, Frank LD. COVID-19 and transport: findings from a world-wide expert survey. Transport Policy. 2021;103:68-85.
32. Boons F, Doherty B, Köhler J, Papachristos G, Wells P. Disrupting transitions: Qualitatively modelling the impact of Covid-19 on UK food and mobility provision. Environmental Innovation and Societal Transitions. 2021;40:1-19.

33. Combs TS, Pardo CF. Shifting streets COVID-19 mobility data: Findings from a global dataset and a research agenda for transport planning and policy. Transportation Research Interdisciplinary Perspectives. 2021;9:100322.

34. Molloy J, Schatzmann T, Schoeman B, Tchervenkov C, Hintermann B, Axhausen KW. Observed impacts of the Covid-19 first wave on travel behaviour in Switzerland based on a large GPS panel. Transport Policy. 2021;104:43-51.

35. Tan L, Ma C. Choice behavior of commuters' rail transit mode during the COVID-19 pandemic based on logistic model. Journal of Traffic and Transportation Engineering (English Edition). 2021;8(2):186-95.

36. Kazemzadeh K, Koglin T. Electric bike (non)users' health and comfort concerns pre and peri a world pandemic (COVID-19): A qualitative study. Journal of Transport \& Health. 2021;20:101014.

37. Torrisi V, Ignaccolo M, Inturri G, Tesoriere G, Campisi T. Exploring the factors affecting bike-sharing demand: evidence from student perceptions, usage patterns and adoption barriers. Transportation Research Procedia. 2021;52:573-80.

38. Rothengatter W, Zhang J, Hayashi Y, Nosach A, Wang K, Oum TH. Pandemic waves and the time after Covid-19 - Consequences for the transport sector. Transport Policy. 2021;110:225-37.

39. Friedman A. Car-Free Environments and Shared Streets. In: editor.^editors. Fundamentals of Sustainable Urban Design. ed.: Springer. 2021 p. 181-6.

40. Azhari JR. Melihat Jalur Sepeda di Lima Kota Dunia, Bisa Jadi Contoh Bagi Jakarta; 2019. 